\title{
Quantifying the Value of Flexibility in Supply Chains for High-Risk Products
}

\author{
John Maleyeff ${ }^{1}$ \\ ${ }^{1}$ Lally School of Management \& Technology, Rensselaer Polytechnic Institute, Hartford, USA \\ Correspondence: John Maleyeff, Lally School of Management \& Technology, Rensselaer Polytechnic Institute, \\ Hartford, CT, 06120, USA. E-mail: maleyj@rpi.edu
}

Received: April 2, 2014

doi:10.5430/jms.v5n2p16
Accepted: April 17, $2014 \quad$ Online Published: May 3, 2014

URL: http://dx.doi.org/10.5430/jms.v5n2p16

\begin{abstract}
A model is developed to motivate financially-driven decision makers in companies that make high-risk products to invest in infrastructural changes to support postponement or other forms of flexibility. Data collected at the manufacturer of a high-risk product forms the basis of the effort. The model is used to estimate the magnitude of costs associated with a traditional speculative supply strategy. A customized version of the classic newsvendor model is developed and applied, based on non-normal demand distributions and carrying costs. It is shown that a speculative strategy based on capacity smoothing and production cost minimization can result in excessive overstock, understock, and inventory carrying costs. Specifically, a cost increase of $52 \%$ can be expected when production is initiated nine months prior to peak sales. The cost increase is reduced to $24 \%$ if the product is produced three months prior to peak sales. The model can help supply chain managers convince corporate executives of the need to redesign the supply chain for speed and flexibility.
\end{abstract}

Keywords: inventory, newsvendor, supply, forecasting, responsiveness

\section{Introduction}

In recent years, unprecedented changes in consumer markets have complicated the life of supply chain planners. In global markets, for example, language differences, cultural conventions, and government regulations create the need for multiple versions of a single product (The Economist, 2000). In the pharmaceutical industry, technological barriers, stringent regulatory requirements, customer cost containment efforts, risk of litigation, and competition from generic manufacturers have all contributed to the inability to forecast demand with precision (Kiely, 2004). These changes have increased the prevalence of products that could be classified as "high-risk" due to their shorter life cycles and more uncertain demand as compared to products in the past. Other examples of high-risk supply chain environments include fashion clothing, personal computers, gourmet candy, toys, book publishing, entertainment offerings, and certain cosmetics (for example, see Napoli, 2001; and Langabeer and Stoughton, 2001). In response to these challenges, a move from "speculative" supply chain strategies (that rely on accurate forecasts and the minimization of supply chain costs to achieve competitiveness) to various "postponement" supply chain strategies (that delay supply decisions as long as possible) have been recommended (Johnson and Anderson, 2000; Pagh and Cooper, 1998). Lean approaches, based on the Toyota Production System, that create pull mechanisms in place of push mechanisms have also been recommended (Zylstra, 2005).

Accurate forecasting of high-risk products is difficult, such as when a new product has sales that will follow a seasonal sales pattern. Examples include the December holiday season, the summer vacation season, and the start of the school year. Demand forecasts in these markets cannot be expected to provide precise demand projections since little or no demand history would be available (Kurawarwala and Matsuo, 1996). In the U.S., manufacturers of consumer products face the additional challenge of dealing with a few large, and powerful, retailers. A common practice is for the retailer to order small quantities of a large number of diverse products and then, for the few products that sell well, follow with much larger orders. This practice would appear to make accurate long term forecasting of high-risk products especially problematic and prone to significant errors. Whatever the source of forecast errors, their effect can be considerable. Kahn (2003) quantified the financial effect of forecasting errors and concluded that a small percentage improvement can result in significant savings. 
Supply chain managers who follow a traditional speculative cost minimization strategy will likely plan to produce a few large batches of each product (in order to minimize unit production cost) and schedule the production of these batches well in advance of the peak selling season (in order to smooth capacity). This operational strategy, however, is only successful when the product's forecast is accurate. A manufacturer of high-risk products who wishes to provide good service to its customers has two choices: (a) create and carry a significant amount of finished goods inventory, which will result in high carrying and overstock costs; or (b) redesign the supply chain for flexibility and speed, which will result in higher production costs. Some authors have recommended the latter strategy, arguing that overall costs are minimized (Pagell et al, 2000). However, many organizations find it difficult to make major improvements in operational flexibility, due to physical or cultural constraints. For example, a manufacturer may be part of a global conglomerate where some component parts are manufacturing at one or two centralized locations. Or, a manufacturer whose executives are focused on cost management may find it difficult to reconcile the benefits of flexibility, which are hidden from direct view of the accountants, over cost minimization, which are highly visible as direct costs in accounting ledgers.

This article was created as a result of a comprehensive project with a consumer product manufacturer that is increasingly selling high-risk products. An analysis was conducted to determine the nature of the uncertainty in demand forecasts, including: (1) the relationship between forecast accuracy and the length of time between the forecast creation and the peak sales season, and (2) the statistical distribution of the demand uncertainty. The preliminary hypotheses, which were confirmed by the analysis, were that the accuracy of the forecast would become improved when made closer to the peak selling season, and that the statistical distribution would follow a right-skewed pattern, since anecdotally it appeared the a few "winners" but many "losers" existed among the products offered for sale. A model was then developed and used to explore financial considerations associated with speculative versus postponement strategies for supply chain planning of high-risk products. While many supply chain managers will find the results of the model expected, the model is useful due to its ability to: (1) accurately estimate the magnitude of costs associated with a speculative strategy, and (2) motivate financially-driven executives to invest in infrastructural changes to support postponement or other forms of flexibility.

\section{Forecast Accuracy Analysis}

At the company analysed in this study, the tendency in recent years has been towards products with a very short lifespan, combined with an increased focus on products that would be classified as high-risk. The products are bought for the most part as gifts and sold in greatest quantity during the December holiday season. The analysis described below is based on a sample of 122 products that were sold in a recent year. The first official forecast was made about 12 months prior to the beginning of the peak selling season. This forecast was made so that a long term capacity plan could be developed and so that some production could be initiated due to a desire to smooth capacity. In order to evaluate forecast accuracy across a range of products, the data had to be standardized to provide an apples-to-apples comparison. So, for each product, the actual sales as a percentage of the sales forecast was calculated. For example, the value $150 \%$ would be used in the case where a product with an annual forecast of 28,000 units had actual sales of 42,000 units. And the value $80 \%$ would be used in the case where a product with an annual forecast of 50,000 units had actual sales of 40,000 units.

Figure 1 is a histogram of actual sales as a percentage of forecasted sales for the 122 products based on the "first" forecast. The distribution is skewed right and the data show a very high level of uncertainty. In mathematical terms, the coefficient of variation (COV) which measures the standard deviation as a percentage of the mean was $134 \%$. The appearance of a right-skewed distribution was not surprising to forecasters at this company. That is, planners noticed that typically a few products would have sales many times higher than the forecasted sales. The right-skewed pattern indicates that for most products, the actual sales will be below forecasted amount. In this case, $57 \%$ of the products had values less than $100 \%$, meaning that the sales were less than the forecasted amount. Most surprising, however, were the relative magnitudes of the differences between actual sales and forecasted sales. In these data, $12 \%$ of the products had actual sales of at least twice the forecasted sales, and $7 \%$ had actual sales over four times the forecasted sales. On the other hand, $28 \%$ of the products had actual sales less than $50 \%$ forecasted sales and $7 \%$ had actual sales less than $25 \%$ of forecasted sales. 


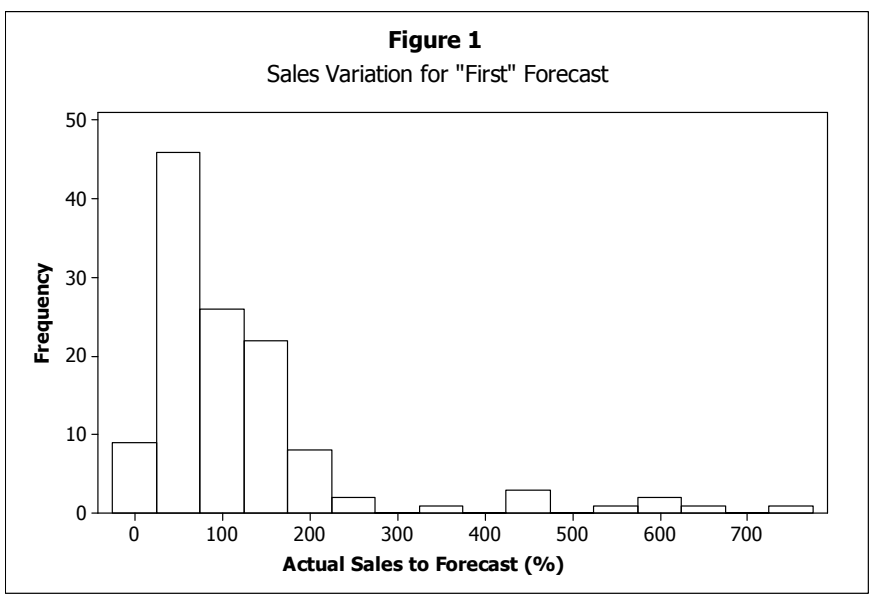

Figure 1. Sales variation for "first" forecast

Other error analyses were based on new forecasts made during subsequent three month increments. The revised forecasts made use of early sales activity up until the date of the forecast. Historically, consumer preferences for birthday gifts will correlate with consumer preference for holiday gifts. Figure 2 is a histogram of actual sales as a percentage of forecasted sales for the 122 products based on a "second" forecast made about 9 months prior to the peak selling season. The distribution is again right-skewed and the COV is $46 \%$. Figure 3 shows corresponding results where a "third" forecast was made about 6 months prior to the peak selling season. The distribution is right-skewed and the COV is $56 \%$. Figure 4 is a similar display based on a "fourth" forecast made about 3 months prior to the peak selling season. A right-skewed distribution is again evident and the COV is $30 \%$. In each case of Figures $2-4$, the about $60 \%$ of products had actual sales less than forecasted sales.

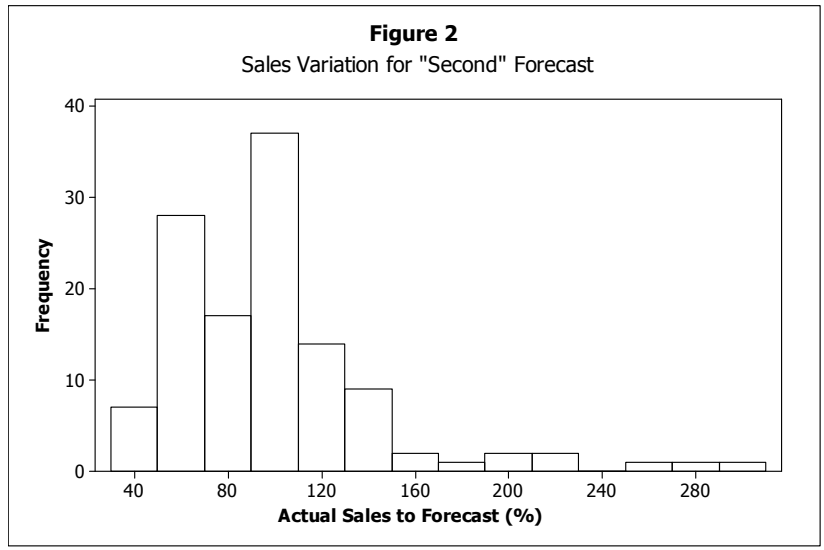

Figure 2. Sales variation for "second" forecast

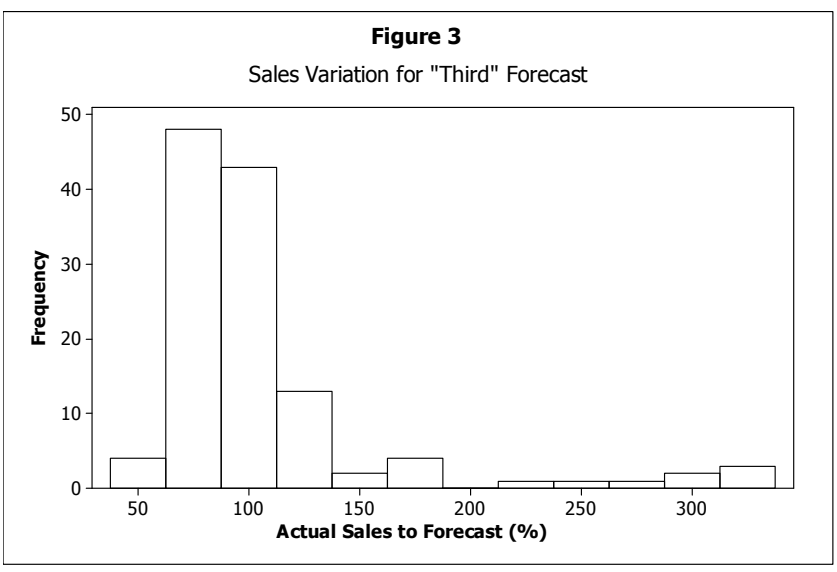

Figure 3. Sales variation for "third" forecast 


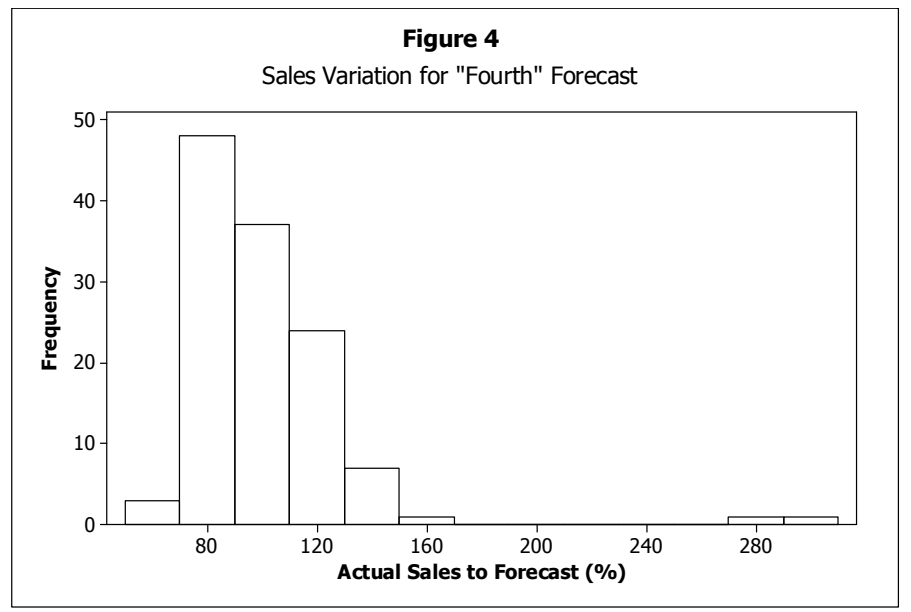

Figure 4. Sales variation for "fourth" forecast

Management and forecasters at this company were in agreement that the initial forecast will always be highly inaccurate. Therefore, a decision was made to attempt to identify lower-risk products and initiate production of large quantities early in the year, and wait for early sales data before committing to significant production quantities of higher-risk items. The commitment to flexibility in the supply chain, however, remained an open issue. Interestingly, the analysis of forecast error distribution detailed above shows a significant improvement in ability to forecast sales after only 3 months of early sales data, decreasing from a COV of $134 \%$ to $46 \%$. This result is consistent with work reported by Harvard researchers showing a significant reduction of forecast error for fashion clothing after $20 \%$ of sales were realized (Fisher and Raman, 1996). If the manufacturer can wait to commit production capacity until a few months prior to the peak selling season, another significant improvement can be expected, down to a COV of $30 \%$. Hence, the focus of this article will be on the comparison of expected costs under three alternative conditions: (1) production capacity is committed 9 months prior to the peak selling season, (2) production capacity is committed 3 months prior to the peak selling season, and (3) production capacity is committed just before the peak selling season. The latter case may be infeasible but is used for illustrative purposes.

\section{Statistical Analysis of Forecast Accuracy}

The results above were considered to be representative of future results. So, a decision was made to develop a mathematical model that would quantify financial considerations under the assumption that the supply planners would create optimal plans given the information available. To create the model, a statistical distribution must be assumed. Traditionally, inventory models employ the normal (bell shaped) pattern. But the model for high-risk products must make use of a right skewed pattern similar to the histograms provided in Figures 1-4. The statistical distribution that most closely resembles the patterns shown on the histograms is called the three-parameter Gamma distribution. The gamma distribution is typically right skewed and includes two parameters: a shape parameter $(\alpha)$ and a scale parameter $(\beta)$. A third parameter may be added, called the threshold parameter $(\tau)$. In the current context, the threshold parameter would represent the smallest potential sales quantity. For example, a mutually agreed upon initial shipment from manufacturer to retailer could control the value of $\tau$. Mathematical details are provided in Appendix A.

To illustrate the use of the three-parameter gamma distribution, sample sales variation curves were developed assuming a forecast of 1000 units. Figure 5 is based on forecasts made 9 months prior to the peak selling season and Figure 6 is based on forecasts made 3 months prior to the peak selling season. The parameters for the gamma distributions were estimated directly from the data shown as histograms in the corresponding Figures 2 and 3. In Appendix B, a method for estimating the three parameters of the Gamma distribution is suggested. 


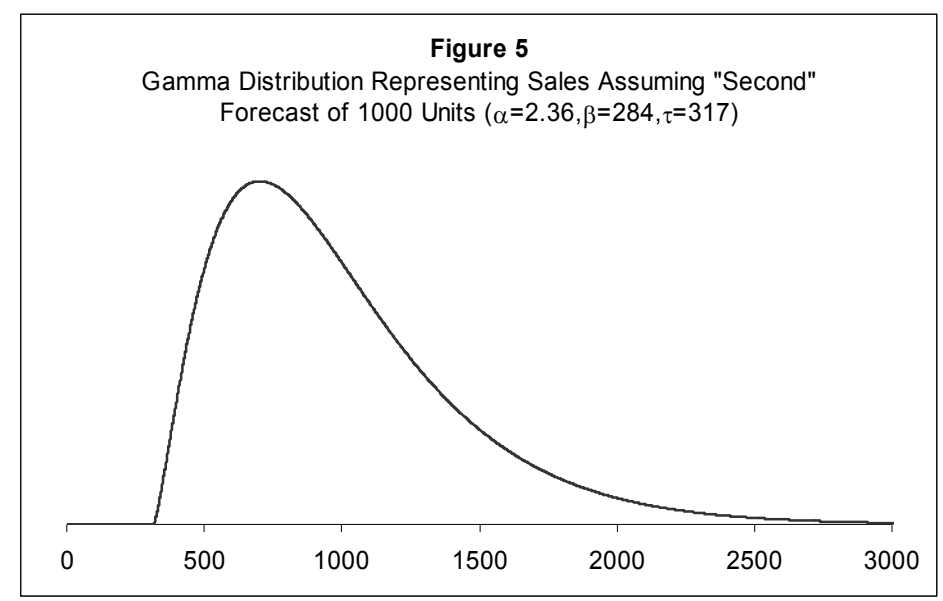

Figure 5. Gamma distribution representing sales assuming "second" forecast of 1000 units $(\alpha=2.36, \beta=284, \tau=317)$

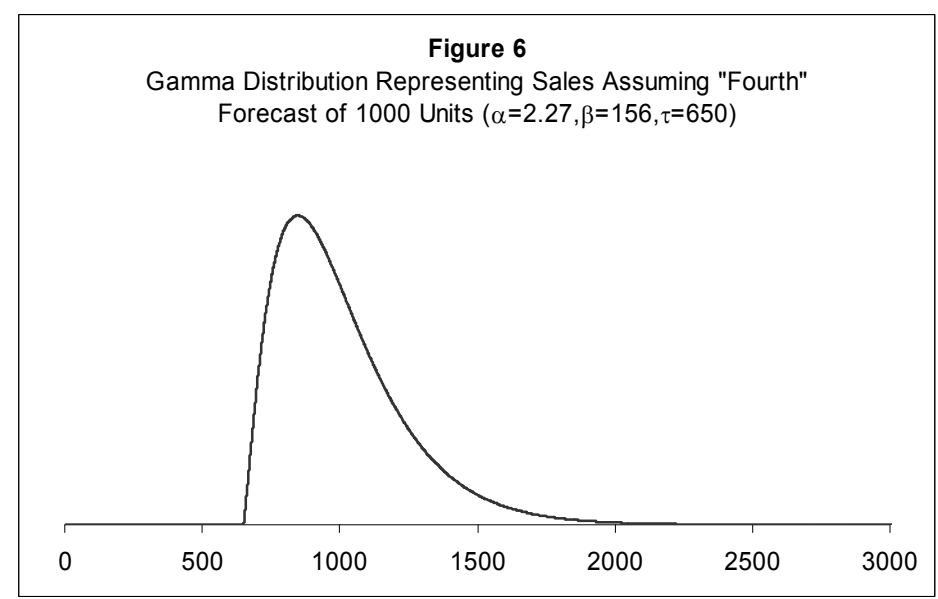

Figure 6. Gamma distribution representing sales assuming "fourth" forecast of 1000 units $(\alpha=2.27, \beta=156, \tau=650)$

\section{Classical Newsvendor Model}

A model often employed to deal with short lifespan products is the classical single-period "newsvendor" model (Khuja 1999). With this model, a single planning period is assumed and inventory is created to cover an uncertain sales forecast. Costs are incurred when the quantity produced is lower than sales (an understock cost) or when the quantity produced is higher than sales (an overstock cost). The total expected cost is shown as Equation 1, where $\mathrm{C}_{\mathrm{U}}$ and $\mathrm{C}_{\mathrm{O}}$ are the per units costs of an understock and an overstock, respectively, and where $\mathrm{X}$ is the random variable representing demand, with $\mathrm{f}(\mathrm{x})$ providing the probability density function for demand.

$$
\mathrm{E}(\text { Cost })=\mathrm{C}_{\mathrm{O}} \int_{0}^{\mathrm{Q}}(\mathrm{Q}-\mathrm{x}) \mathrm{f}(\mathrm{x}) \mathrm{dx}+\mathrm{C}_{\mathrm{U}} \int_{\mathrm{Q}}^{\infty}(\mathrm{x}-\mathrm{Q}) \mathrm{f}(\mathrm{x}) \mathrm{dx}
$$

The order quantity expression that minimizes the expected cost, $Q^{*}$, is shown as Equation 2, where $F(x)$ is the cumulative distribution function for the random variable, $\mathrm{X}$ :

$$
F\left(Q^{*}\right)=\frac{C_{U}}{C_{O}+C_{U}}
$$

In words, the optimal order quantity $\left(\mathrm{Q}^{*}\right)$ is the value of $\mathrm{Q}$ such that the probability of demand being less than $\mathrm{Q}$ is $\frac{\mathrm{C}_{\mathrm{U}}}{\mathrm{C}_{\mathrm{O}}+\mathrm{C}_{\mathrm{U}}}$. Traditionally, the demand distribution is assumed to be normal. When this is the case, a standard normal table is typically employed to obtain $\mathrm{Q}^{*}$. This classical newsvendor model does not apply to high-risk products, but 
has been modified by others to account for unusual conditions, and will be modified below to account for high-risk scenarios.

Other authors that have made modifications to the newsvendor model have accounted for alternative operational environments. When the demand distribution is right-skewed, a common approach is to transform the random variable so that it approximates a bell shape. For example, a Box-Cox transformation may be helpful (Hinkley and Runger, 1984). Some authors have reported on the formulation of the newsvendor model with other than normal demand. For example, Li, Lau, and Lau (1991) created a newsvendor model in the case of exponentially distributed demand. Godfrey and Powell (2001) presented a newsvendor model in the case of an unknown (and not necessarily bell shaped) demand distribution. Their model, however, does not generate optimal solutions as accurately as a corresponding parametric model. Scarf (1958, Chapter 12) developed a minimax, distribution-free newsvendor model which assumes that the mean and variance of demand are known and that the demand distribution is the worst possible given the known parameters. Finally, Kurawarwala and Matsuo (1996) considered an integrated forecasting and inventory management approach for short life cycle products. Their work requires no previous sales history and is tested using data at a personal computer manufacturer.

Probabilistic inventory models have previously been used to quantify the benefits of flexible supply chain management systems. Moon and Choi (1996) used a distributional free model (where only the mean and standard deviation of demand are known) to compare a make-to-order approach to make-to-stock. Gurnani and Tang (1999) presented a newsvendor model where a retailer may order a seasonal product twice during a selling season. In their formulation, normality is assumed and the unit cost for the second order is uncertain. Lee and Tang (1997) used a stochastic model to explore delayed product differentiation where demand is normally distributed. Their analysis considers various forms of differentiation, including modular design. Stochastic dynamic programming was used by Eppen and Iyer (1997) to determine optimal policies for retailer-manufacturer agreements that allow for the delay of partial shipments pending the analysis of early sales data. Kouvelis and Gutierrez (1997) created a centralized global newsvendor formulation and use the formulation to show that a decentralized approach is suboptimal. Eynan and Rosenblatt (1995) used a stochastic two-echelon inventory model to compare make-to-order with make-to-stock policies, explicitly accounting for more favorable manufacturing costs in the make-to-stock environment. Their models allow for an assumption that potentially sales decrease in the make-to-order environment since products are not readily available.

\section{Customized Newsvendor Model}

In creating an alternative model that would apply to this manufacturer, the following decision scenario is assumed. Some months prior to the realization of customer demand, a decision is made to produce a product and the optimal order quantity is to be determined. A carrying cost is incurred since production is initiated prior to the realization of sales. The carrying cost increases in direct proportion to the length of time between production and sales. If the order quantity exceeds sales, then an overstock cost is incurred. Alternatively, if sales exceed the order quantity, then understock cost is incurred. Demand is assumed to follow a three-parameter gamma distribution. Demand forecasts made closer to the realization of demand will have a smaller level of forecast uncertainty compared with production decisions made earlier.

To accommodate the scenario described above, two modifications to the traditional newsvendor model are made. First, carrying costs are included. These carrying costs would not include allowances for anticipated overstock or understock costs, which are accounted for explicitly in the model. The choice of an optimal production quantity and resulting minimum cost is based on Equation 3, which provides the expected cost based on Q, the quantity produced. $\mathrm{C}_{\mathrm{O}}, \mathrm{C}_{\mathrm{U}}$, and $\mathrm{C}_{\mathrm{H}}$ and the per unit costs of overstocks, understocks, and carrying, respectively.

$$
\mathrm{E}(\operatorname{Cos} \mathrm{t})=\mathrm{C}_{\mathrm{O}} \int_{0}^{\mathrm{Q}}(\mathrm{Q}-\mathrm{x}) \mathrm{f}(\mathrm{x}) \mathrm{dx}+\mathrm{C}_{\mathrm{U}} \int_{\mathrm{Q}}^{\infty}(\mathrm{x}-\mathrm{Q}) \mathrm{f}(\mathrm{x}) \mathrm{dx}+\mathrm{C}_{\mathrm{H}} \mathrm{Q}
$$

The order quantity expression that minimizes the expected cost is $\mathrm{Q}^{*}$ as shown as Equation 4.

$$
\mathrm{F}\left(\mathrm{Q}^{*}\right)=\frac{\mathrm{C}_{\mathrm{U}}-\mathrm{C}_{\mathrm{H}}}{\mathrm{C}_{\mathrm{O}}+\mathrm{C}_{\mathrm{U}}}
$$

The second change to the traditional newsvendor application is that the demand distribution is assumed to be three-parameter gamma. The Excel function $=\operatorname{GAMMAINV}(p, \alpha, \beta)+\tau$ may be used to determine the optimal order 
quantity, where $p=\frac{C_{U}-C_{H}}{C_{O}+C_{U}}$, and where $\alpha, \beta, \tau$ are the shape, scale, and threshold parameters of the demand distribution.

\section{Analysis}

The revised newsvendor model was used to quantify costs incurred by the manufacturer during a typical year. The model was first exercised using conditions agreed upon by management for a production decision made nine months prior to the peak selling season. Expected costs for overstocks, understocks, and carrying were calculated based on the optimal order quantity using Equations 3 and 4. The integrations required to perform the expected cost calculation were done numerically in Excel. Then, the optimal order quantity and expected cost were determined using conditions assumed to be in place for a production decision made three months prior to the peak selling season. The resulting cost expectations can, in turn, be compared to the ideal just-in-time scenario where production would be made to an actual order, and none of the costs accounting for in the model would be incurred. The results are presented in Table 1 and discussed below.

Table 1. Flexibility analysis using revised newsvendor model

\begin{tabular}{lccc} 
& \multicolumn{3}{c}{ Production Initiated (Months Prior to Peak Sales Season) } \\
\cline { 2 - 4 } & 9 & 3 & 0 \\
\hline Forecast Error COV & $50 \%$ & $30 \%$ & $0 \%$ \\
\hline Exp. Understock Cost & $17.9 \%$ & $7.9 \%$ & $0 \%$ \\
\hline Exp. Overstock Cost & $11.3 \%$ & $8.7 \%$ & $0 \%$ \\
\hline Exp. Carrying Cost & $22.9 \%$ & $7.5 \%$ & $0 \%$ \\
\hline Exp. Total Cost & $52.1 \%$ & $24.1 \%$ & $0 \%$ \\
\hline
\end{tabular}

Consider the case where a production decision is made nine months prior to the peak selling season. A forecast made this early in the year can be expected to have a COV of about $50 \%$. In this analysis, to enhance the generalization of results, all costs are based on a unit product cost of $\$ 10.00$. Costs for understock $\left(\mathrm{C}_{\mathrm{U}}\right)$ and overstock $\left(\mathrm{C}_{\mathrm{O}}\right)$ are assumed to be $\$ 17$ and $\$ 3$, respectively. These cost assumptions would generate results for any case where the selling price is $270 \%$ higher than the cost of manufacture. The results are also generalized to the case where items remaining on the shelf at the end of the product's lifespan are liquidated at $70 \%$ of the cost of manufacture. The carrying cost rate is assumed to be $24 \%$ per year. Hence, given the nine month duration between production and sales, $\mathrm{C}_{\mathrm{H}}=\$ 1.80$, which is generalized to $18 \%$ of the items manufacturing cost. Using Equation 4 , the value of $\mathrm{F}\left(\mathrm{Q}^{*}\right)$ is calculated to be 0.76 , meaning that the probability of sales exceeding the optimal order quantity is 0.76 .

The three-parameter gamma distribution assumed in this case would have a threshold located 1.5 standard deviation units less than the mean, and a shape parameter of 2.25 (derived using Equation B-2). Assuming that sales are forecast to be 1,000 units, the scale parameter would be 333 (derived using Equation B-1). The following Excel function provides the optimal order quantity of 1270 units: $=\operatorname{GAMMAINV}(0.76,2.25,333)+250$. Solving for Equation 3 , the expected cost would be $\$ 5.21$ per unit. The expected cost results are easily generalized. Specifically, under the best conditions, a product incurs a 52\% higher cost due to the decision to produce the item 9 months prior to the selling season. Interestingly, a study by Schweitzer and Cachon (2000) concluded that supply managers tend to make decisions that differ significantly from the mathematically optimal. Specifically, mangers tend to generate too much inventory of low product margin items and too little inventory of high profit margin items. Hence, many managers are likely to incur even higher costs using this production strategy.

As a comparison, consider the case where the production decision is made three months prior to the peak selling season. In this case, the forecast error COV would be about 30\%. Based on a forecast is for 1000 units, the gamma distribution would have a threshold parameter of 550, a shape parameter of 2.25, and a scale parameter of 200. Again, the product incurs a unit cost of $\$ 10$, and the costs for understock and overstock are $\$ 17$ and $\$ 3$, respectively. The carrying cost rate remains $24 \%$ per year. Here, the optimal order quantity is 1244 and the resulting expected cost is $\$ 2.41$ per unit.

These results show that even a modest improvement in sales forecast, combined with a delay in production, reduces the expected costs of carrying, overstock, and understock by over half, from $52 \%$ of the item's cost to $24 \%$ of the item's cost. It also shows the value of a highly flexible manufacturing system that could, in the best of conditions, produce to order and thus remove all costs assumed in the revised newsvendor model. In reality, these cost improvements must be compared with the cost of the flexibility itself (excess capacity, overtime, small batches, outsourcing, etc.). For example, flexibility that adds $10-20 \%$ to the cost of manufacturing would appear to be 
justified if a considerable reduction in lead time could be achieved. At the company analyzed, these results showed that under current conditions, it is likely that the excess costs exceed the company's expected profit margin in many cases. The results convinced management of the need to seriously consider the reduction of lead time within their supply chain.

\section{Conclusion}

In this article, the newsvendor model was revised for conditions in place at a manufacturer of high-risk products with a short lifespan, highly uncertain demand, and where the manufacturer faces pressure from retailers to provide rapid replenishment. The analysis shows that a significant cost increase results from the practice of producing large inventories well in advance of anticipated sales. The cost impact can be mitigated using two strategies: (a) the strategic use of capacity rather than inventory to buffer against sales uncertainty, and (b) the strategic choice of products to produce early in the year based on lower projected forecast errors.

The limitations in this work are twofold and suggest future research directions. First, the model as presented would need to be applied to specific organizations based on their own product forecasting abilities, cost structures, and supply chain design options. Perhaps future research could approach the challenge of developing more conceptual guidelines that would be generally applicable. Second, in today's global supply chains that are geographically dispersed and culturally diverse, lead times are themselves subject to a great deal of uncertainty. Extending the assumptions of the model to encompass the types and magnitudes of lead time uncertainty would help decision makers make informed risk mitigation decisions.

\section{References}

Anonymous. (2000). All yours. The Economist, 355(8164), 57-58.

Eppen, G.D., \& A.V. Iyer. (1997). Backup agreements in fashion buying - the value of upstream flexibility. Management Science, 43(11), 1469-1484. http://dx.doi.org/10.1287/mnsc.43.11.1469

Eynan, A., \& M.J. Rosenblatt. (1995). Assemble to order and assemble in advance in a single-period stochastic environment. Naval Research Logistics, 42, 861-872. http://dx.doi.org/10.1002/1520-6750(199508)

Fisher, M.L., \& A. Raman. (1996). Reducing the cost of demand uncertainty through accurate response to early sales. Operations Research, 44(1), 87-99. http://dx.doi.org/10.1287/opre.44.1.87

Godfrey, G.A., \& W.B. Powell. (2001). An adaptive, distribution-free algorithm for the newsvendor problem with censored demands, with applications to inventory and distribution. Management Science, 47(8), 1101-1112. http://dx.doi.org/10.1287/mnsc.47.8.1101.10231

Gurnani, H., \& C.S. Tang. (1999). Note: Optimal ordering decisions with uncertain cost and demand forecast updating. Management Science, 45(10), 1456-1462. http://dx.doi.org/10.1287/mnsc.45.10.1456

Hinckley, D.V., \& G. Runger. (1984). The analysis of transformed data (with discussion). Journal of the American Statistical Association, 79(3), 302-320. http://dx.doi.org/10.1080/01621459.1984.10478045

Johnson, M.E., \& Anderson, E. (2000). Postponement strategies for channel derivatives. International Journal of Logistics Management, 11(1), 19-35. http://dx.doi.org/10.1108/09574090010806047

Kahn, K.B. (2003). How to measure the impact of a forecast error on an enterprise? The Journal of Business Forecasting, 22(1), 21-25.

Khouja, M. (1999). The single-period (newsvendor) problem: Literature review and suggestions for future research. OMEGA, 27, 537-553. http://dx.doi.org/10.1016/S0305-0483(99)00017-1

Kiely, D. (2004). The state of pharmaceutical industry supply planning and demand forecasting. The Journal of Business Forecasting Methods \& Systems, 23(3), 20-22.

Koschat, M.A., Berk, G.L., Blatt, J.A., Kunz, N.M., LePore, M.H., \& S. Blyakher. (2003). Newsvendors tackle the newsvendor problem. Interfaces, 33(3), 72-84. http://dx.doi.org/10.1287/inte.33.3.72.16010

Kouvelis, P., \& G.J. Gutierrez. (1997). The newsvendor problem in a global market: Optimal centralized and decentralized control policies for a two-market stochastic inventory system. Management Science, 43(5), 571-585. http://dx.doi.org/10.1287/mnsc.43.5.571

Kurawarwala, A.A., \& H. Matsuo. (1996). Forecasting and inventory management of short life-cycle products. Operations Research, 44(1), 131-150. http://dx.doi.org/10.1287/opre.44.1.131 
Langabeer, J., \& T. Stoughton. (2001). Demand planning and forecasting in the high technology industry. The Journal of Business Forecasting, 20(1), 7-10.

Lee, H.L., \& C.S. Tang. (1997). Modelling the costs and benefits of delayed product differentiation. Management Science, 43(1), 40-53. http://dx.doi.org/10.1287/mnsc.43.1.40

Li, J., Lau, H., \& A.H. Lau. (1991). A two-product newsboy problem with sacrificing objective and independent exponential demands. IIE Transactions, 23(1), 29-39. http://dx.doi.org/10.1080/07408179108963839

Moon, I., \& S. Choi. (1997). Distribution free procedures for make-to-order (MTO), make-in-advance (MIA), and composite policies. International Journal of Production Economics, 48, 21-28. http://dx.doi.org/10.1016/S0925-5273(96)00026-6

Napoli, P.M. (2001). The unpredictable audience: An exploratory analysis of forecast error for new prime time network television programs. Journal of Advertising, 30(2), 53-60. http://dx.doi.org/10.1080/00913367.2001.10673637

Pagell, M., Newman, W.R., Hanna, M.D., \& D.R. Krause. (2000). Uncertainty, flexibility, and buffers: Three case studies. Production and Inventory Management Journal, First Quarter, 35-43.

Pagh, J.D., \& Cooper, M.C. (1998). Supply chain postponement and speculation strategies: How to choose the right strategy. Journal of Business Logistics, 19(2), 13-33.

Scarf, H. (1958). A min-max solution of an inventory problem. Studies in the Mathematical Theory of Inventory and Production, Stanford University Press, California, USA.

Schweitzer, M.E., \& G.P. Cachon. (2000). Decision bias in the newsvendor problem with a known demand distribution: experimental evidence. Management Science, 46(3), 404-420. http://dx.doi.org/10.1287/mnsc.46.3.404.12070

Zylstra, K. (2005). Distribution made lean. Industrial Engineer, 37(1), 31-35.

\section{Appendix A}

The three-parameter gamma density function is shown as Equation A-1, while its mean and variance provided as Equations A-2 and A-3, respectively.

$$
\begin{gathered}
f(x-\tau)=\frac{1}{\beta^{\alpha} \Gamma(\alpha)} x^{\alpha-1} e^{-\frac{(x-\tau)}{\beta}}, x>\tau \\
\mu=\alpha \beta+\tau \\
\sigma^{2}=\alpha \beta^{2}
\end{gathered}
$$

\section{Appendix B}

It is not easy to independently set location, dispersion, and threshold parameters for the gamma distribution as is the case with the normal distribution in setting values for $\mu$ and $\sigma$. However, at other companies, it has been reported that groups of similar products will have demand that will varies according to similar patterns. For example, Koschat et al (2003) write that when a similar product is sold in different locations, products having the same mean demand will have the same level of demand dispersion. For the products analyzed, it was observed that the threshold parameter tended to consistently fall about $\mathrm{k}=1.5$ standard deviation units less than the mean value. Assuming a specific value of $k$, the shape and scale parameters can then be estimated based on the forecast $(\mu)$ and the standard deviation of the forecast error $(\sigma)$, according to Equations B-1 and B-2.

$$
\begin{aligned}
& \beta \cong \frac{\sigma}{\mathrm{k}} \\
& \alpha \cong \mathrm{k}^{2}
\end{aligned}
$$

For example, if the forecast were for 1,000 units and the COV was estimated to be $40 \%$, then the threshold parameter would be set at 400 , the scale parameter would be set at 267 , and the shape parameter would be set at 2.25 . 